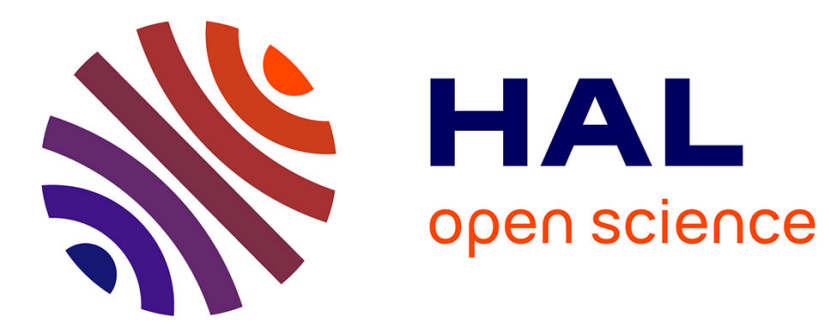

\title{
Closing the TIMES Integrated Assessment Model (TIAM-FR) Raw Materials Gap with Life Cycle Inventories
}

\author{
Antoine Boubault, Seungwoo Kang, Nadia Maïzi
}

\section{> To cite this version:}

Antoine Boubault, Seungwoo Kang, Nadia Maïzi. Closing the TIMES Integrated Assessment Model (TIAM-FR) Raw Materials Gap with Life Cycle Inventories. Journal of Industrial Ecology, inPress, 10.1111/jiec.12780 . hal-01652739v2

HAL Id: hal-01652739

https://hal-mines-paristech.archives-ouvertes.fr/hal-01652739v2

Submitted on 21 Aug 2018

HAL is a multi-disciplinary open access archive for the deposit and dissemination of scientific research documents, whether they are published or not. The documents may come from teaching and research institutions in France or abroad, or from public or private research centers.
L'archive ouverte pluridisciplinaire HAL, est destinée au dépôt et à la diffusion de documents scientifiques de niveau recherche, publiés ou non, émanant des établissements d'enseignement et de recherche français ou étrangers, des laboratoires publics ou privés. 


\section{Closing the TIMES integrated assessment model}

\section{(TIAM-FR) raw materials gap with life-cycle}

\section{inventories}

Antoine BOUBAULT*, Seungwoo KANG, Nadia MAÏZI

MINES ParisTech, PSL Research University, Center for Applied Mathematics, rue Claude Daunesse, CS 10207, 06907 Sophia Antipolis, France

*antoine.boubault@mines-paristech.fr

\section{Summary}

Integrated assessment models are in general not constrained by mineral resource supply. In this paper, we introduce a material accounting method as a first step towards addressing the raw materials gap in the TIMES Integrated Assessment Model (TIAM-FR version). The method consists in attributing process-based life-cycle inventories (LCIs) taken from the ecoinvent 3.3 database to the TIAM-FR technology processes constituting the global energy system. We demonstrate the method performing a prospective exercise on the electricity-generating sector in a second shared socio-economic pathway (SSP2) baseline scenario on the 2010-2100 time horizon. We start by disaggregating the LCIs into three separate life phases (construction, operation, and decommissioning) and coupling them to their respective TIAM-FR electric outputs (new capacities, electricity production, and end-of-life capacities) in order to estimate the annual mineral resource requirements. Prospective uses of fossil fuels and metallic and nonmetallic mineral resources are quantified dynamically at the life phase and regional levels (15 world regions). The construction of hydropower, solar and wind power plants generate increasing use of metallic and nonmetallic mineral resources in successive peak and valley periods. However, the use of fossil fuels is much higher than the use of mineral resources all along the 
horizon. Finally, we evaluate how sensitive the global material use is to the allocation of a share of infrastructure activities to the decommissioning phase. This approach could be extended to other integrated assessment models and possibly other energy sectors.

\section{Keywords}

Raw materials; Integrated assessment models; Prospective scenario; TIMES; TIAM-FR; ecoinvent; Life-cycle inventories; Integrated assessment; Material flow analysis

\section{Introduction}

Following the recent development of large-scale integrated assessment models (IAMs), it is possible to investigate the complexity of anthropogenic energy systems, their interactions with Earth systems, and their multiscale evolution. Among the variety of existing models, global models stand out due to their wide scope, comprehensive overview and finite nature (resources come from the environment only, not as imports from other regions). The most authoritative projections, such as the IEA's World Energy Outlook (International Energy Agency 2016), the EIA’s International Energy Outlook (U.S. Energy Information Administration 2017) and the WEC's World Energy Scenarios (World Energy Council 2016) provide global energy scenarios constrained by physical, technological, and economic drivers, as well as environmental policies. These models result from bottom-up, top-down or hybrid descriptions of the global energy system following optimized (function minimization) or simulated development trajectories that satisfy a set of constraints. Although these have become increasingly integrated and complex using large quantities of data, they typically do not consider nonfuel material availability, stocks, flows, transformations, functions and services.

World energy scenarios usually assume growing economic demand. This results in the development of industrial supply chains that require increasing primary energy and materials. In 2015 , about $81 \%$ of world's primary energy production consisted in fossil energy carriers. More than a quarter $(26.5 \%)$ of the world's primary energy supply (13.6 Gtoe) was directed to electricity and combined heat-and- 
power (CHP) plants in the form of fossil energy carriers (International Energy Agency 2017), as

shown by Figure 1. This share increased steadily for decades (dotted line) until stabilizing recently.

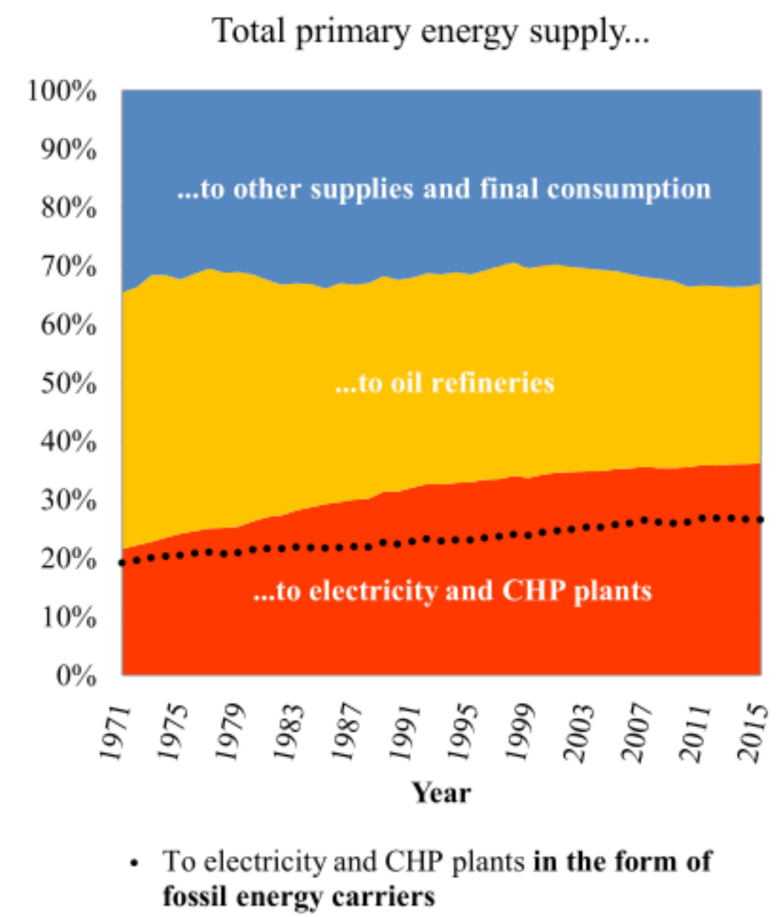

Figure 1: Distribution of total primary energy supply (TPES) to main energy sectors. 2015 TPES (IEA): 13.6 Gtoe. The dotted line shows the share of TPES that is supplied to electricity and CHP plants exclusively as fossil energy carriers

In the context of sustainable development, removing fossil fuels from electricity-generating (EG) technologies will require the widescale development of renewable energy technologies. Multiple prospective studies deduce that more materials — especially metals — could be required in the coming decades following the projected development of low-carbon and energy-efficient technologies (Van Vuuren et al. 1999; Halada et al. 2008; Gerst 2009; Graedel 2011; Kleijn et al. 2011; Keramidas et al. 2012; Elshkaki and Graedel 2013; Vidal et al. 2013). These suggest that available material reserves and processing capabilities might not be sufficient to cover future material needs, driven by economic growth and environmental constraints. This perspective leads to two complementary questions: 1) What are the implications of long-term prospective scenarios for mineral resources? and 2) What are the impacts of a constrained mineral resource supply on long-term prospective scenarios? 
Determining the answer to the first question would bring valuable knowledge about potential highlydemanded mineral resources in the future, and it could be used to achieve more efficient resource management (Ali et al. 2017) and more resilient material supply chains, thus mitigating stress periods. Addressing the second question would provide elements to determine whether or not mineral resources should be considered in a given scenario. For instance, scenarios not taking into account adequate mineral resource supply could be irrelevant or might need to be reassessed in light of new resource supply constraints. Ideally, the two questions above are addressed together using a systems approach. From this perspective, a study of the mutual interaction between raw materials and prospective energy scenarios is relevant and may be analyzed using different industrial ecology tools like material flow analysis (MFA) and life-cycle assessment (LCA). In this direction, Hertwich et al. performed a prospective integrated life-cycle assessment of global electricity generation to 2050 , based on IEA's 2015 Energy Technology Perspective report (Hertwich et al. 2015). Their work revealed that LCA metrics carry crucial information that needs to be considered by both energy system modelers and climate policymakers. Currently, life-cycle metrics are rarely considered in integrated assessment models (Pauliuk and Hertwich 2016; Pauliuk et al. 2017), although some studies aim to cover this gap for greenhouse gas emissions (GHG) (Daly et al. 2015; Pehl et al. 2017; McDowall et al. 2018) and for other life-cycle impacts (Arvesen et al. 2018).

In this paper, we address question 1) above and make a first step towards representing mineral resource use in the TIMES integrated assessment model (TIAM-FR version). TIAM-FR is a bottomup integrated assessment model that was developed by the Energy Technology Systems Analysis Program (ETSAP) group of the IEA (Loulou and Labriet 2008). It provides decision-makers with prospective multiregional energy scenarios. Its bottom-up description of the energy system allows us to access the life-cycle material footprint of each technology using life-cycle inventories (LCIs). At that point, we introduce a novel but straightforward life-cycle material accounting method to estimate the life-cycle material use of EG technologies. First, we describe the method that attributes LCIs to the TIAM-FR EG processes. In particular, the technologies' LCIs are disaggregated into three phases: construction, operation and decommissioning, in order to represent each technology's use of fossil 
fuels and mineral resources over time. Second, using TIAM-FR we determine a scenario following a baseline second shared socioeconomic pathway (SSP2) as described by (O’Neill et al. 2014). Third, the prospective requirements of fossil fuels and metallic and nonmetallic mineral resources in EG technologies are estimated on the 2010-2100 horizon. Results at the regional scale are provided. Fourth, we investigate how sensitive the total material use is to a change in the allocation of infrastructure LCIs between the construction and the decommissioning phases. Finally, we provide perspectives relating to the full integration of nonfuel raw materials into TIAM-FR.

\section{Method}

\section{The TIAM-FR model}

TIAM is a bottom-up model in the TIMES family and was created in the framework of the ETSAP group at the IEA. TIAM-FR is the TIAM version that has been developed at MINES Paristech Center for Applied Mathematics to address energy and climate-related questions (Dubreuil et al. 2013; Selosse and Ricci 2014; Kang et al. 2017). It depicts the global energy system with a high level of disaggregation on energy sources, technologies, and end uses. A Reference Energy System (RES) connects commodities to current and future technologies in different energy supply sectors (upstream [fuel processing], heat, electricity) and end-use sectors (agriculture, commercial, industry, residential and transportation). The RES includes the collection, transformation, distribution, trade and end-use of main energy carriers including fossil energy carriers, bioenergy and uranium. These material commodities have defined resource supply curves (fossil resources, uranium) or potentials (solar, bioenergy, hydro and wind energy). They are converted into energy-equivalent quantities to be monitored and processed in a common accounting unit. Demand for steel, iron, pulp, and non-ferrous metals is also defined in the model, but only as an exogenous driver for the industrial sectors concerned. The individual supply of mineral resources is not modeled. In each of the 15 world regions represented (Africa, Australia and New Zealand, Canada, China, Central and South America, Eastern Europe, Former Soviet Union, India, Japan, Middle East, Mexico, Other Developing Asian countries, 
South Korea, United States of America, Western Europe), TIAM-FR establishes a balance between supply technologies and a set of forty-two demand drivers including gross domestic product (GDP) growth (supp. Figure 1), population growth (supp. Figure 2), demand for electricity, heat, transportation, lighting, hot water, etc. (Loulou and Labriet 2008). The model computes the total net present value of the total annual cost of all activities, discounted at $5 \%$ from the selected reference year 2010, and then it optimizes the technological landscape until a least-cost solution is found. The optimization is performed on 11 periods the lengths of which are provided in supplementary Table 1. Perfect competition and full foresight are assumed in the TIAM-FR model. These assumptions lead to economically ideal situations rather than forecasts, from where real phenomena and future pathways can be discussed and compared. A shared socioeconomic pathway 2 (O’Neill et al. 2014) baseline scenario is investigated where no climate constraints are set. This means the world follows a "business-as-usual" trajectory leading to a 2100 temperature rise ranging from between $2.5^{\circ} \mathrm{C}$ and $3{ }^{\circ} \mathrm{C}$ compared to the preindustrial era.

The full model is used, but only the EG sector is analyzed due to a wide coverage of main EG technologies in the ecoinvent LCI database, and a consensus about the increasing need for electricity in the future, whether or not climate targets are achieved. The 103 current and future electricitygenerating processes that constitute the EG sector in TIAM-FR are grouped into ten categories: bioenergy, coal, geothermal, hydropower, oil, natural gas, nuclear energy, marine, solar photovoltaics, solar thermal, and wind. Individual technologies, classification, and service lifetimes can be found in the supplementary material (supp. Table 2). Most of them are documented with their current and future costs and performance on the ETSAP-TIAM community's website (Energy Technology Systems Analysis Program). Three electricity-related outputs are reported: the newly-installed electric capacities in GW, the electricity production in PW h, and the end-of-life capacities in GW. These quantities are annualized over each period by dividing by the period's length.

\section{Life-cycle inventories}

The ecoinvent 3.3 database is currently one of the largest process-based life-cycle inventory databases 
(Wernet et al. 2016). In ecoinvent, available activities, products and technologies are built from elementary processes. This structure makes it a consistent framework for life-cycle assessment (LCA) and product comparisons. Simapro 8.3 software is used to extract the LCIs.

LCIs rely on the definition of system boundaries, which describe what flows of energy, mass, and other substances enter and exit the system. ecoinvent's EG technologies datasets generally include a foreground list including all activities directly related to the construction, operation (comprising fuel extraction and transport), maintenance, and decommissioning of the power plants, and a background system comprising "upstream" and "downstream" activities such as material extraction, processing, transportation, and waste treatment. In this study, we aim at quantifying the life-cycle material requirements (or footprint) of EG technologies in order to determine what categories of materials will be most sensitive to electricity production. This is why we consider direct and indirect use of material flows and stocks but do not differentiate them. Thus, accumulation of stocks and outflows are not investigated. Several calculation methods are available depending on how foreground and background activities are linked to form a system (European Commission et al. 2010, 70-72). We opt for the default "allocation at the point of substitution" method and discuss the choice of an allocation method rather than a consequential method in the supplementary material (supp. section 4). Other databases and literature that could complement missing data or provide more "balanced" estimates were intentionally avoided for consistency, transparency and reproducibility purposes. The only external LCI we use is a $100 \mathrm{MW}$ solar tower dataset that was provided by (San Miguel et al. 2016; Corona et al. 2016) to represent concentrated solar power technologies for which no dataset was found in ecoinvent. Regular updates, verified data and a large number of users make the ecoinvent database suitable for comparing datasets, filling data gaps and spotting unrealistic or inconsistent assumptions (Steubing et al. 2016).

\section{Fossil fuels and mineral resources}

Each LCI comprises a list of substances that are involved in the technology's activity within the selected boundaries. Substances may be energy, materials (solids, liquids, gases) or other LCA- 
pertinent indicators, such as land occupation and transformation. Categorizing raw materials can be difficult and requires establishing definitions. In this study, we use the Committee for Mineral Reserves International Reporting Standards' definition of mineral resources, which describe the latter as "a concentration or occurrence of solid material of economic interest in or on the Earth's crust in such form, grade or quality, and quantity that there are reasonable prospects for eventual economic extraction"(Drielsma et al. 2016). Following this definition, mineral resources are divided into two categories: metallic and nonmetallic mineral resources. A specificity of ecoinvent is that some materials such as metals are reported not as refined products nor as ores, but as resource contents in crude ore, distinguishing all individual valuable resources. Thus, a metallic mineral resource refers to the metal content in metal ore. Fossil fuels (including peat) are considered in a separate category. We define raw materials as a more general category of natural resources of economic interest including mineral resources, fossil fuels, biomass, water, and other liquids and gases. We choose to restrict the scope of this study to fossil fuels and metallic and nonmetallic mineral resources that are found in the 'resource' compartment and 'in ground' sub-compartment as defined in ecoinvent (peat, located the 'biogenic' sub-compartment, is also considered a fossil fuel). A list of mineral resources and their categories can be found in the supplementary material (supp. Table 3).

\section{Combining LCIs with TIAM-FR outputs}

Our objective is to quantify and compare the amount of fossil fuels and metallic and nonmetallic mineral resources extracted and consumed by the EG technologies, not only in direct processes but also in upstream activities indirectly contributing to these processes. To do so, we attribute each TIAM-FR process with an LCI.

A variety of electricity-producing technologies are documented in ecoinvent, but not each of the 103 TIAM-FR technology processes has a corresponding LCI (e.g. concentrating solar power, marine and carbon capture and sequestration technologies). This is why the same LCI is attributed to all processes in a similar technical family (e.g. marine and wind offshore technologies are considered in the same technical family, and thus, are attributed with the same LCI dataset. However, wind offshore is 
grouped with wind onshore in the "wind" technological category, and not the "marine"). Furthermore, the availability of ecoinvent's LCI datasets for different world regions allows us to select a corresponding dataset for each of the 15 world regions in TIAM-FR. A nearby region, or the "Rest-ofWorld" dataset is used when a given region is not available in the database. As the technologies' service lifetimes are approximately equivalent in ecoinvent and TIAM-FR, no corrections are made to the LCIs or to the TIAM-FR processes.

LCIs of EG processes list all substances according to the functional unit $\mathrm{kg} /(\mathrm{kW} \mathrm{h})$. This format is ideal for rating technologies that have short lifetimes and invariable life-cycle phases. However, it is not convenient for analyzing long-lifetime technologies with a high variability of material use throughout their construction, operation, and decommissioning phases. Furthermore, a single massper-electricity-output figure is often not adequate to represent the intensity of the technology's impacts (e.g. material use, $\mathrm{CO}_{2}$ emissions, etc.) when they occur for a relatively short period of time (e.g. construction of a hydropower dam). In the TIAM-FR model, installed capacities may produce electricity intermittently or not at all, depending on the model constraints. For these technologies, a minimum of three phases - construction, operation, and decommissioning — seems reasonable to capture the differences in their material use over their life cycle. In this case, a convenient feature is the introduction of an additional functional unit: $\mathrm{kg} / \mathrm{W}$, for the construction and decommissioning phases where, instead of electricity, a capacity is produced (or removed). We propose to follow the evolution of life-cycle material use evolution in the three phases, multiplying each functional unit by their corresponding electric output in the scenario. A similar approach, where material consumption is assumed to be linearly driven by the production of a unit service — in our case a kilowatt or a kilowatthour - is common in the material flow-stock literature, e.g. (B. Müller 2006) who used floor space per capita as a driver for housing material stock dynamics. Such an approach requires identifying the life phase in which each activity occurs, which is not always documented in ecoinvent. For instance, construction, repairs and decommissioning activities are usually merged in an "infrastructure" category, while other activities are available in a "transformation" category. In order to overcome the life-phase separation issue, we make the following approximation: first, 
"transformation" activities are allocated to the operation phase; second, activities related to the power plant's infrastructure are allocated between the construction and decommissioning phases. We use a ratio $\alpha$ to set a percentage of the infrastructure LCI that is attributed to the decommissioning phase, while the complementary part, $1-\alpha$, is attributed to the construction phase. Practically, this coarse approximation can be interpreted as if part of the construction of new power plant was instead performed during the decommissioning phase of an end-of-life power plant of the same type being replaced. This enables us to evaluate the sensitivity of the total material use to more or less materialintensive construction and decommissioning phases, while maintaining consistency and mass balance with the original infrastructure LCI. A more refined life-phase separation method was recently proposed by (Arvesen et al. 2018) in order to combine LCIs with IAMs.

In this study, we use "system" LCIs, which means direct and upstream material requirements appear in an aggregated form. The available infrastructure LCIs (construction + decommissioning phases) are first expressed in $\mathrm{kg}$ of materials required to produce one power plant. These materials are then divided by their corresponding power capacities to yield $\mathrm{kg} / \mathrm{W}$ figures. The transformation LCIs (operation phase) are shown by the unit $\mathrm{g} /(\mathrm{kW}$ h). Figure 2 shows the schematic disaggregation method and coupling with the TIAM-FR outputs. The construction LCI is multiplied by the new capacities, the operation LCI is multiplied by the electricity production, and the decommissioning LCI is multiplied by the retiring (or end-of-life) capacities. The LCI datasets and their attribution to the TIAM-FR technology processes are detailed in the supplementary material (supp. Table 4).

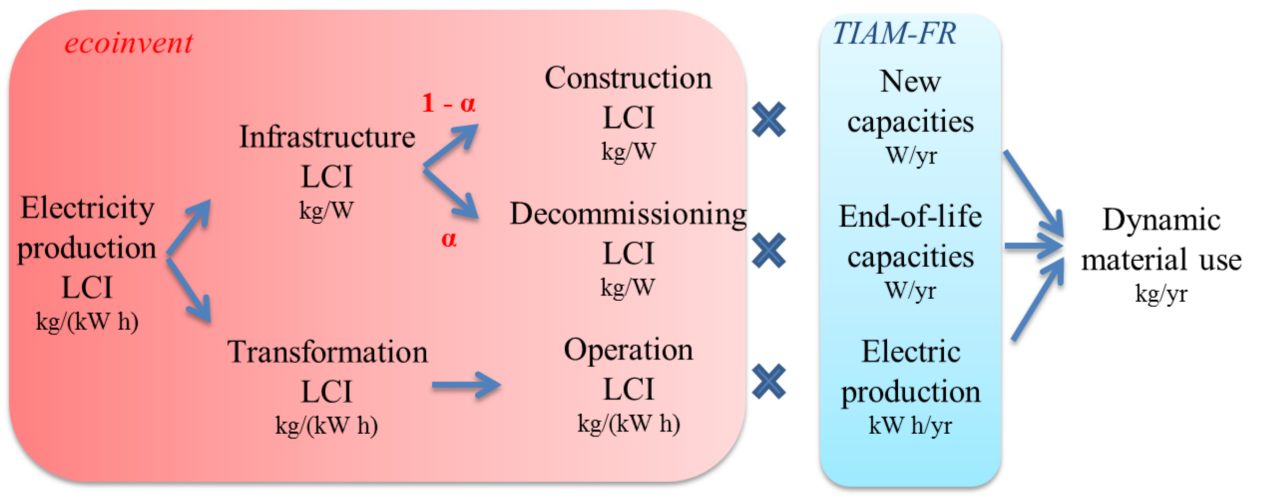

Figure 2.Disaggregation method and coupling of technologies' LCIs to the TIAM-FR outputs 


\section{Results}

\section{TIAM-FR scenario}

Figure 3 shows the TIAM-FR scenario outputs. New and end-of-life power plant capacities are relative to the reference year (2010). Global electricity production grows from $21 \mathrm{PW} \mathrm{h}$ in 2010 to $45 \mathrm{PW} \mathrm{h}$ in 2050, and $61 \mathrm{PW} \mathrm{h}$ in 2100. In 2050, it is mostly generated by coal power plants with $20.0 \mathrm{PW} \mathrm{h}$, followed by natural gas (8.5 PW h), hydropower (5.6 PW h), and nuclear (4.1 PW h). Solar and wind technologies become key electricity producers from 2040 (8.6 PW h and 5.1 PW h in 2100, respectively). Other sources of electricity production like oil, marine, bioenergy, and geothermal energies together contribute less than $10 \%$ of total generation. New power capacities of gas and coal increase until 2050 when they fluctuate in the range of $65-120 \mathrm{GW} / \mathrm{yr}$. Wind capacity increases rapidly but is caught up by solar photovoltaics (PV) in 2040, which reach a global average installation rate of $90 \mathrm{GW} / \mathrm{yr}$ in the second half of century. Nuclear, marine and hydro power plants develop slightly and reach annual new capacities of $5 \mathrm{GW} / \mathrm{yr}$ to $25 \mathrm{GW} / \mathrm{yr}$. Bioenergy electricity production (2.7 PW h in 2050) is supported by new methane abatement technologies (e.g. biogas). However, these technologies have no defined capacities and, thus, their infrastructure cannot be considered (only material use during operations is considered). End-of-life capacities consist mostly of coal, natural gas, and nuclear power plants before 2040. An increasing number of wind farms and solar power plants are decommissioned in the second half of the century. Periods with increased end-of-life capacities are generally compensated by new capacities to support the growing electricity production. 


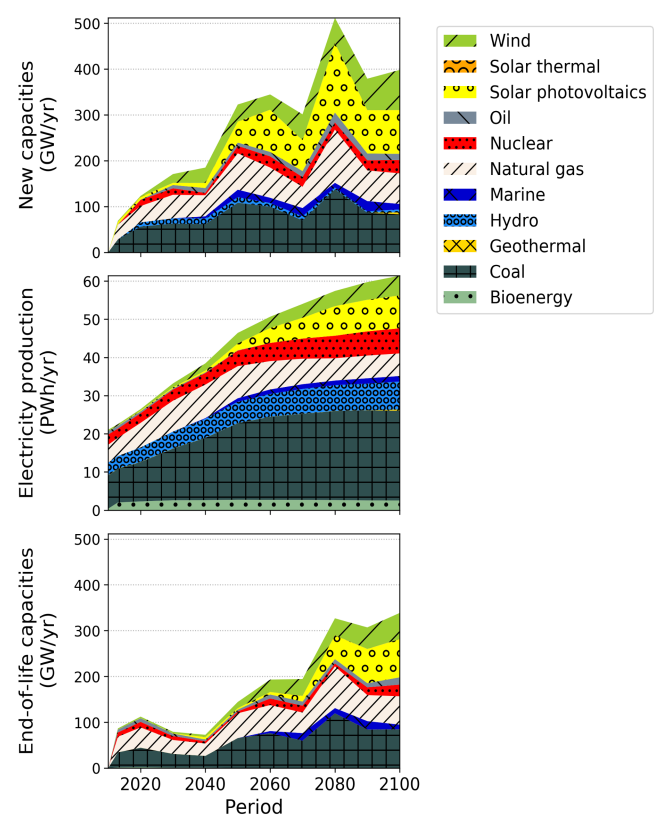

Figure 3. Annual new capacities, electricity production, and end-of-life capacities in a second shared socioeconomic pathway baseline scenario obtained using the TIAM-FR model

\section{Life-cycle material use of electricity-generating technologies}

Figure 4 shows the sum of the masses of all fossil fuels and mineral resources used in the infrastructure and operation phases of each power-generating technology, averaged over the time periods and regions. There is a clear distinction between fossil and bioenergy power plants versus alternative technologies. Fossil fuel and bioenergy technologies have lower material requirements for their infrastructure - below $0.7 \mathrm{~kg} / \mathrm{W}$ - but high material consumption during operation $-120 \mathrm{~g}$ / (kWh) (bioenergy) to $664 \mathrm{~g} /(\mathrm{kWh})$ (coal) — due to the large quantities of fuels consumed. Of the fossil energy technologies, natural gas demonstrates the lowest material needs for both infrastructure and operation due to its higher efficiency and lighter infrastructure. Coal and oil power plants have additional mechanical and chemical processing steps for fuel and wastes management. In contrast with fossil fuel technologies, alternative technologies have higher material needs for their infrastructure from $1 \mathrm{~kg} / \mathrm{W}$ (wind, solar, and marine technologies) to $132 \mathrm{~kg} / \mathrm{W}$ (hydropower) — but lower needs 
when operating, at about $5 \times 10^{-5} \mathrm{~g} /(\mathrm{kWh})$ (solar PV) to $0.1 \mathrm{~g} /(\mathrm{kWh})$ (wind).

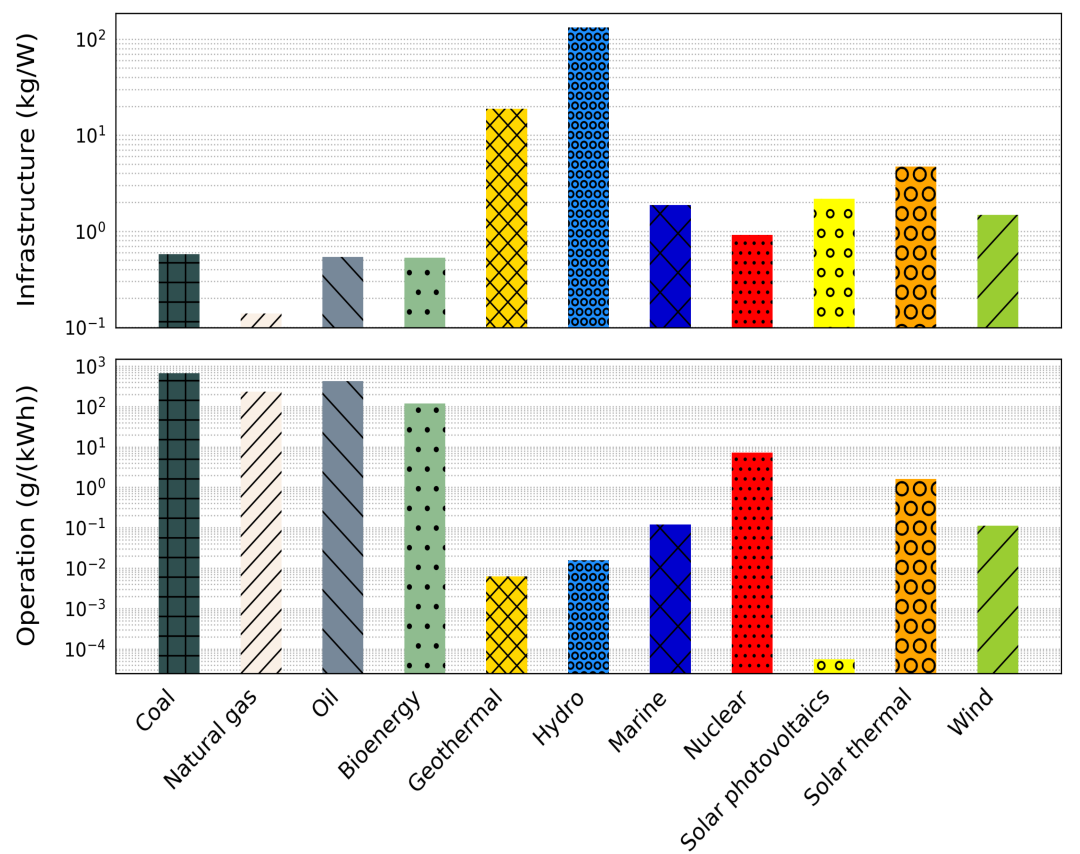

Figure 4. Materials requirements in the infrastructure (construction + decommissioning) and operation phases of main electricity generation technologies. The units used are $\mathrm{kg} / \mathrm{W}$ for infrastructure phases and $\mathrm{g} /(\mathrm{kWh})$ for the operation phase. Values are averaged on regions and periods

Nuclear plants have intermediate material requirements for both the infrastructure and operation phases at $0.9 \mathrm{~kg} / \mathrm{W}$ and $7 \mathrm{~g} /(\mathrm{kW} \mathrm{h})$, respectively. Solar thermal (concentrating solar power) has higher infrastructure requirements than nuclear but use fewer materials during operations. The large variations observed among the technologies reflect the very different ways materials are involved in the construction, operation and decommissioning life phases across the technologies.

Life-cycle material use of EG technologies is generally very sensitive to location, size, and technology vintage (Gibon et al. 2017). This is especially the case for hydropower dams, for which large amounts of materials can be displaced and huge quantities of cement and steel can be required depending on the construction site. This is confirmed by IPCC AR5 (fig. 7.6, Bruckner et al. 2014), where hydropower has the greatest uncertainty and the largest GHG emission range. Figure 5 shows the life-cycle use of aluminum, copper and iron by several EG technologies, according to this study (ecoinvent 3.3), and studies by (Hertwich et al. 2015) and (de Koning et al. 2018). 


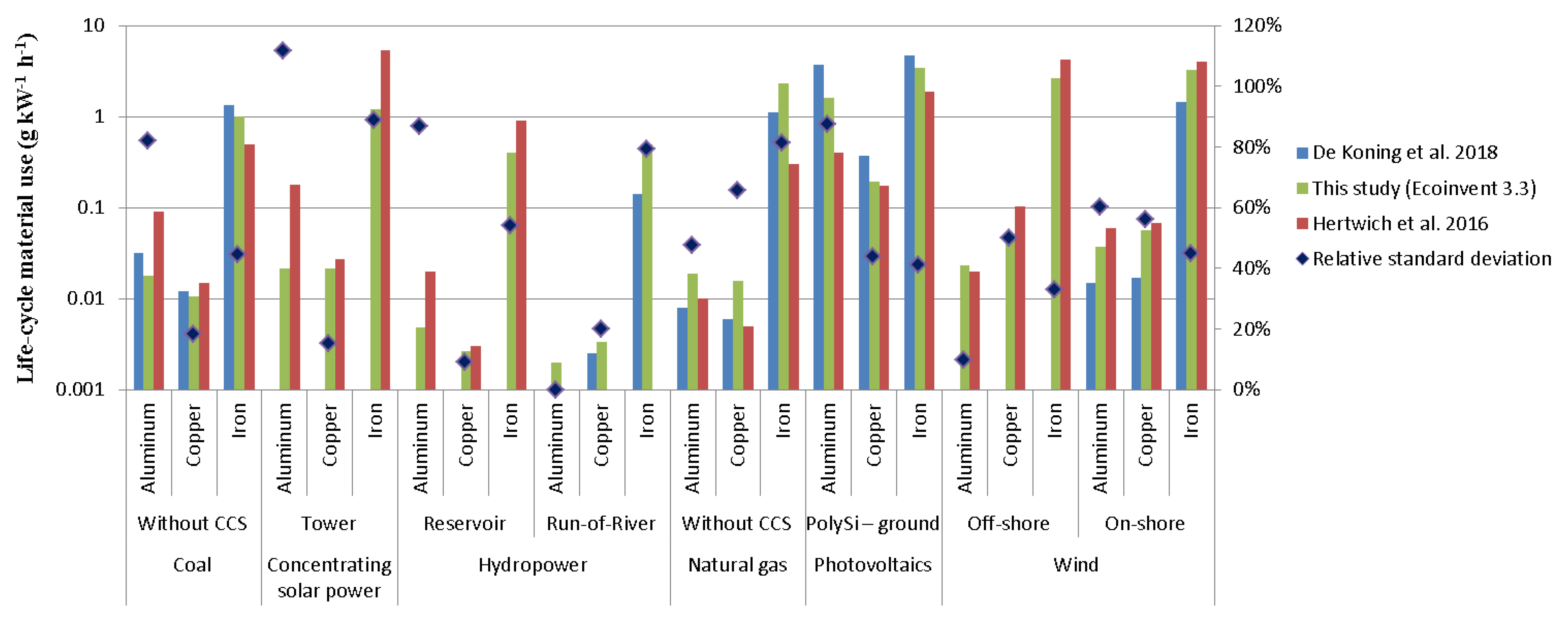

Figure 5. Life-cycle use of aluminum, copper and iron by several electricity-generating technologies analyzed in this study compared to (Hertwich et al. 2015) and (de Koning et al. 2018)*. The relative standard deviation is the sample's standard deviation divided by its mean.

*The types of hydropower, photovoltaics and wind technologies reported by de Koning were not provided. They are subsequently assumed to be hydro run-of-river, ground-based solar polySi and wind on-shore for better representation

The relative standard deviation values between the three data sources are less than $100 \%$ for most technologies and materials, except for the use of aluminum in the solar tower dataset $(112 \%)$.

Observed differences are due to the consideration of different technologies, especially for coal and natural gas. Another reason is that (Hertwich et al. 2015) used custom LCIs with a hybrid approach combining process-based LCIs and a multiregional environmentally extended input-output database to cover economic activities that are not addressed in process-based LCIs (Gibon et al. 2015). Therefore, some activities may be considered in their analysis that are truncated in ecoinvent 3.3. Nevertheless, the relative uses of the three materials are consistent. A relevant comparison between the technologies and the time periods is thus possible, while the individual value of material use should be interpreted inseparably from the system boundaries (Majeau-Bettez et al. 2011).

We deliberately choose not to adjust nor calibrate the ecoinvent datasets to maintain a high level of reproducibility. As the ecoinvent database is often used for technology comparisons, our approach enables one to identify potential gaps and investigate the convergence between prospective LCI, MFA and integrated assessment modeling.

\section{Material use dynamics}


By coupling the LCIs to the TIAM-FR scenario outputs, we calculate the annual life-cycle material requirements for each technology, by material type. The results are calculated at $\alpha=0.1$, meaning $10 \%$ of each substance in the infrastructure LCI is attributed to the decommissioning phase, and $90 \%$ to the construction phase. This value is inspired by (Hertwich et al. 2015), which assume energy requirements for decommissioning power plants are $10 \%$ of those for their construction.

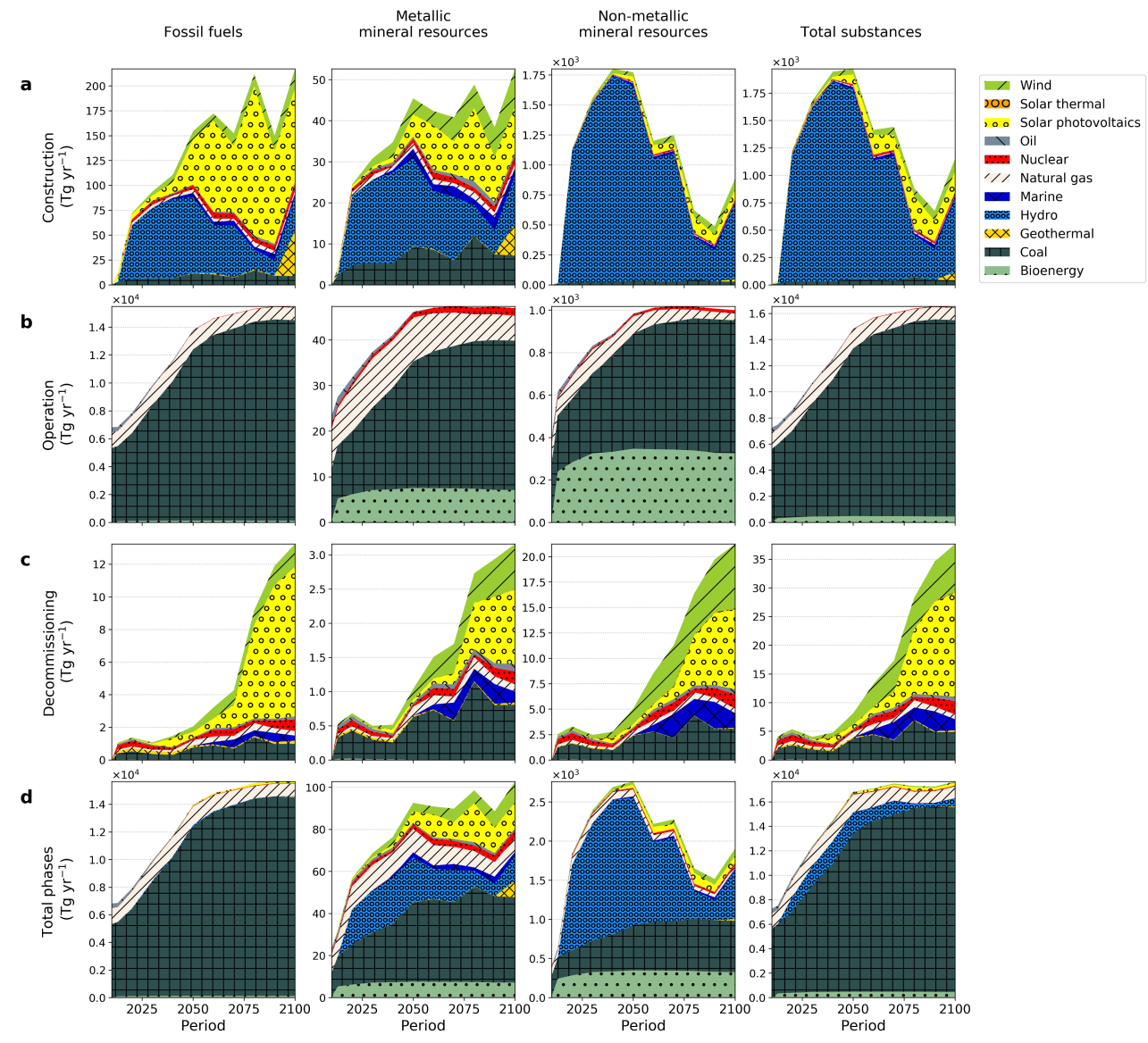

Figure 6. Total annual mass of fossil fuels and metallic and nonmetallic mineral resources needed in the construction, operation, and decommissioning phases. $\alpha=0.1$. Tg/yr: Teragram per year (see full data in supp. Table 5)

Figure 6 shows the life-cycle use of fossil fuels and metallic materials and nonmetallic mineral resources generated by the developing EG technologies (see full data in supp. Table 5). In the construction phase (6a), fossil fuels are mostly used by hydropower in the first half of century (76 Tg/yr in 2050) and by solar PV in the second half (94 Tg/yr in 2100). At the end of horizon, the development of geothermal facilities requires a substantial amount of fossil fuels (46 Tg/yr in 2100). 
Fossil fuel consumption in the construction phase of other technologies (marine, natural gas and nuclear) is $33 \mathrm{Tg} / \mathrm{yr}$ in 2050 and $43 \mathrm{Tg} / \mathrm{yr}$ in 2100 . Looking at material use in the decommissioning phase (6c), about $0.8 \mathrm{Tg} \mathrm{yr}^{-1}$ of fossil fuels are used in the coal and nuclear capacity decommissioning phases. After 2030, decommissioning of solar power plants is responsible for the largest share of fossil fuel use in this phase. However, use of fossil fuels in both the construction and decommissioning phases is negligible compared to the life-cycle amount of fossils burned in coal and natural gas power plants during operations (6b) $(14,380 \mathrm{Tg}$ for coal and $895 \mathrm{Tg}$ for natural gas in 2100). Total annual consumption of fossil fuels (6d) due to EG technologies plateaus in 2090 at 15,648 Tg/yr.

Comparing our results with historical statistics, 2.1 Gtoe of coal and 1.0 Gtoe of natural gas were consumed directly by electricity and CHP plants in 2010 according to (International Energy Agency 2017). This is $3627 \mathrm{Tg}$ of coal and $856 \mathrm{Tg}$ of natural gas, assuming IEA's average net calorific values of $24.05 \mathrm{~kg} / \mathrm{MJ}$ for coal and $50.03 \mathrm{~kg} / \mathrm{MJ}$ for natural gas (International Energy Agency 2005). In contrast, our model gives a life-cycle consumption of $5314 \mathrm{Tg}$ of coal and of $1349 \mathrm{Tg}$ of natural gas in 2010 , which is $47 \%$ and $58 \%$ higher than the direct consumption, respectively. However, IEA statistics do not include the life-cycle effects associated with each sector, which partly explains the difference observed. Another reason is the use of a limited number of LCIs for coal and natural gas technologies (two LCI datasets each) in our analysis.

The use of metallic resources in the construction phase (6a) follows a similar evolution to that of fossil fuels, except for a relatively larger share of metals in coal and wind generation plants, and a lower share in solar power plants (compared to their share of fossil fuels). Metal use due to decommissioning activities (6c) is dominated by coal power plants. Solar and wind end-of-life capacities generate substantial use of metallic resources in the second half of century. The consumption of metals is mostly driven by fossil and bioenergy plants during the operation phase (6b). Total use of metallic mineral resources (6d) is $23 \mathrm{Tg} / \mathrm{yr}$ in 2010 which is in agreement with (Hertwich et al. 2015) which estimated the sum of life-cycle consumption of iron, aluminum and copper by EG technologies at $23 \mathrm{Tg} / \mathrm{yr}$ in 2010, in an IEA baseline scenario. However, use of metallic mineral resources reaches $80-$ 
$90 \mathrm{Tg} / \mathrm{yr}$ by 2050 while it stays constant in their study due to decreasing material intensities.

Most of the nonmetallic mineral resources used are attributable to the new hydropower infrastructure (6a) for which outstanding material use is assumed in the ecoinvent LCI. The total use of nonmetallic materials (6d) tends to decrease after a surge in 2040 resulting from the construction of large hydropower plants. In-operation (6b), consumption of nonmetallic resources is also substantial due to coal, gas, and bioenergy power generation, which displace large amounts of raw materials during mining activities and for the production of biofuels. In the second half of century, decommissioning activities (6c) in solar, wind, coal, marine and nuclear plants generate most of the use of nonmetallic mineral resources. The total material use generated in the decommissioning phase (6c) ranges from $1 \%$ to $3 \%$ of the total material use observed in the construction phase (6a) (at $\alpha=0.1$ ).

The totals plot (6d) shows that the amounts of mineral resources used increase rapidly. The total amounts of mineral resources required to construct power plants (6a) overtakes the amount of mineral resources needed for operations (6b) as early as 2020 , due to the development of hydropower.

However, the amount of fossil fuels and biofuels burnt during the operation phase (6b) by far exceeds the total consumption of mineral resources.

Looking at the total material use in 2100 , China is the highest consumer with about half $(8,385 \mathrm{Tg} / \mathrm{yr})$ of global use of fossil and mineral resources $(17,659 \mathrm{Tg} / \mathrm{yr})$, followed by India $(2,879 \mathrm{Tg} / \mathrm{yr})$ and the USA (2,221 Tg/yr ), while Western Europe (764 Gg/yr ) and other developing Asian countries $(632 \mathrm{Gg} / \mathrm{yr})$ come in 4th and 5th positions. These results feature in more detail in the supplementary material (section 7).

The 2010 global extraction of fossil fuels, metal ores, and nonmetallic minerals were estimated by (Schandl et al. 2017) at 13,300 Tg, 7,200 Tg, 30,700 Tg, respectively. Comparing these estimates with our results, we find electricity and CHP plants were responsible for the life-cycle use of $51.3 \%$ of global fossil fuels (compared to $36 \%$ [4,732 $\mathrm{Tg}]$ according to IEA's direct consumption data and previously assumed calorific values), $0.3 \%$ of global metal ores, and $1.3 \%$ of global nonmetallic minerals in 2010. However, metallic mineral resources only include the metal content in ore, while the 
nonmetal part is considered as nonmetallic mineral resource. Summing all mineral resources - thus overcoming this counting issue - we find $1.1 \%$ of global mineral resources extracted were used in the life-cycle of EG technologies in 2010.

\section{Sensitivity to a material use impact shift towards the decommissioning phase}

When $\alpha$ varies, the material consumption dynamics are modified. Figure 7 shows the total annual use of fossil fuels and metallic and nonmetallic mineral resources for three values of $\alpha$ : $\alpha=0, \alpha=0.5$, and $\alpha=1$. As expected, fossil fuel consumption is not significantly affected by $\alpha$ as most of the fossil fuels are used during the operation phase. When $\alpha$ is higher, material use is lower as there are fewer end-oflife capacities than new ones. The raw mineral resources that were assumed in the construction phase of hydropower are partly shifted to the decommissioning phase (which occurs after 2100 due to an assumed service lifetime of 100 years). Compared to the case where $\alpha=0$, the material requirements at $\alpha=0.5$ in 2050 are $0.5 \%$ for fossil fuels, $20.8 \%$ for metallic mineral resources, and $32.4 \%$ for nonmetallic mineral resources. 

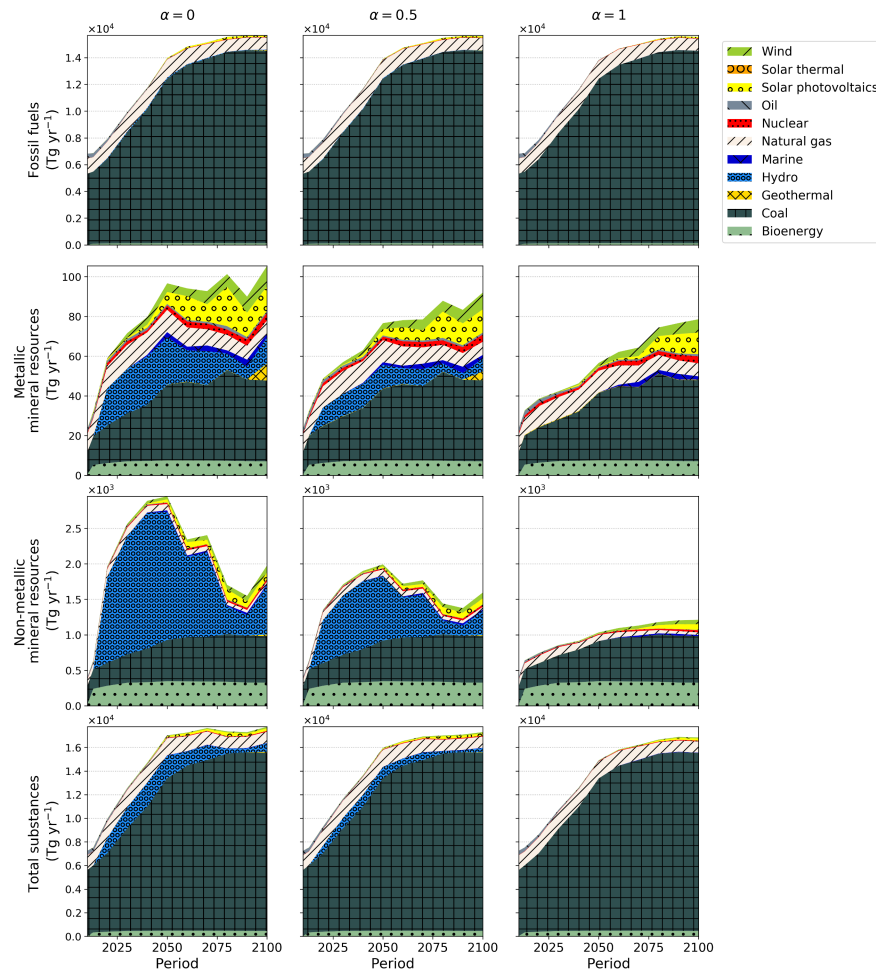

Figure 7. Total annual mass of fossil fuels and metallic and nonmetallic mineral resources due to EG technologies technologies at $\alpha=0, \alpha=0.5$, and $\alpha=1$

\section{Discussion}

The TIAM-FR model — as well as most IAMs — does not consider the mineral resources needed for products and infrastructures in the energy system. This results in prospective scenarios that assume unlimited mineral resource supply. Not only does it prevent IAMs from assessing the impacts of mineral resource cycles and circular economy policies, but it can also generate inconsistencies when energy and climate policies are in fact associated with unrealistic material availability.

The purpose of this prospective exercise is not to predict future material consumption to 2100 but to demonstrate the possibility to combine the bottom-up structure of TIAM-FR with life-cycle inventories to extract valuable information on the relations between energy scenarios and material resource use. Linking the TIAM-FR model with LCIs, we show that the SSP2 scenario investigated has strong implications for fossil fuel and mineral resource use, with a high increase in the use of metallic and nonmetallic mineral resources due to the development of low-carbon EG technologies. A 
specific feature of our approach is that all fossil fuels and mineral resources considered in ecoinvent are analyzed, providing an overview of material consumption in the EG sector. The very different dynamics of material use in the construction, operation and decommissioning phases could not be represented using aggregated LCIs, especially for large and long-lived facilities. Using disaggregated LCIs, we showed that periods of investment in new capacities are associated with a strong increase in the resource requirements. This may in turn generate increasing GHG emissions. Thus, low-carbon solutions must be found at every stages of the life-cycle of renewable energy technologies, from material extraction to recycling and waste disposal. In the same time, a zero carbon emission world is likely to have a much larger mineral resource footprint if economic growth is maintained. Therefore, it is of crucial importance to investigate the material limits to the global energy system's development, and establish circular economy scenarios.

From this perspective, soft-linking IAMs with LCIs can be a convenient and useful solution to energy modelers and decision-makers in performing a first screening of energy and environmental impacts of material resources on various socioeconomic pathways.

Based on the current results, it is not possible to say that EG technologies will face material supply shortages. To answer this question, the present method could be adapted to cover other resourceintensive sectors of the energy system (e.g. tranportation, electricity consumption, or building) using adequate functional units. This would require separating direct from indirect material use for each process LCI to avoid double-counting due to overlapping supply chains. Another important task would be to analyze the material use dynamics of individual resources regarding their specific availability and environmental impacts (e.g. GHG emissions, land use, abiotic resource depletion, etc.). Eventually, such an approach could lead to a full description of material flows in the energy system, and help determine resource constraints not currently considered in IAMs.

Our approach does not circumvent errors in ecoinvent and TIAM-FR, nor does it palliate missing or outdated data. On the contrary, it makes it easier to identify them, and if relevant, to correct them, or submit new datasets. Thus, we would like to invite other integrated assessment modelers to look at the 
nonfuel material issue and develop scenarios that are compatible with industrial ecology principles.

\section{Further work and recommendations}

Life-cycle inventory is one of the most effective tools to compare different technologies or products based on their life-cycle material use. However, datasets often come from different sources, use different data, at different times, and assume different system boundaries and linking models. Expert judgment is thus generally required to combine, harmonize, correct or update existing LCIs, depending on the question addressed. This leads to seemingly more accurate estimates, but also to a profusion of LCI datasets that may be reused in situations where initial data sources are unclear and where their applicability is questionable (Masanet et al. 2013). In this study, we took an alternative route, relying on the ecoinvent database only. This choice also comes with its own issues and limitations. Even though ecoinvent is one of the most complete LCI databases, only a limited number of technologies are represented (e.g. no CCS technologies, no CSP plants). Each has its own data gaps and assumptions, which might not be fully consistent with others, or with their associated TIAM-FR technologies. The LCI system boundaries may generate discrepancies in total material requirements, by including or excluding economic sectors and activities that might — or might not — be included in other LCIs. For example, the hydropower dam infrastructure LCI include large earth movements that end up as wastes, while these wastes could be used for other functions (building, roads, etc.). In addition, the dataset is calculated as an average technology (of Swiss dams) for which no power capacity is explicitly provided.

It was shown previously that process-based LCIs cannot cover all economic sectors and may underestimate material use and environmental impacts by $20 \%-60 \%$ following truncation (MajeauBettez et al. 2011). From this perspective, life-cycle inventory faces the same "bottom-up vs. topdown" issue that took place in the integrated assessment community and led to the development of hybrid IAMs (Hourcade et al. 2006). Hybrid LCI methods represent the "natural" evolution towards analyzing more and more complex systems with a consequential insight. 
(Majeau-Bettez et al. 2011) writes: "the development of generic life cycle data sets should be seen as something more than the mere compilation of individual inventories, but rather as an opportunity to model the metabolism of society". In this direction, segmenting the life cycle of products into multiple phases could provide clearer information for decision-making, and a higher flexibility for modeling time-dependent consequential LCIs.

Ideally, information loss between LCI providers and interpreters should be minimized, and the life phase during which each activity occurs should be preserved, especially for large technologies or products that have heterogeneous material consumption intensities and extended service lifetimes. In this analysis, the LCIs are static and identical by scenario. Using invariable allocation LCIs may create deviations in the material use when the surrounding environment has changed and no longer corresponds to the initial system. The further the horizon, the higher the uncertainty and bias generated by use of static LCIs. To partially address this issue, LCIs can be adjusted according to the evolution of the background system in order to reflect, for example, a more or less carbon-intensive power generation sector (Hertwich et al. 2015; Pehl et al. 2017). However, several key aspects of existing prospective and consequential approaches are left unaddressed, such as the increasing material use of decarboning resource extraction treatment processes, as well as the non-linearities involved in consequential LCIs of technologies, the service lifetime of which may range from 15 years to more than 100 years. Hybrid or consequential LCIs that are tied to a specific scenario may not be more applicable to other scenarios than an allocation approach. This is why consequential LCI needs improvement to make more room for scenario customization (Masanet et al. 2013; Pauliuk et al. 2015), while keeping some representative invariants allowing relevant comparisons.

While LCIs may evolve depending on the scenario, the scenario itself may also be affected by LCIs, especially if technological deployment is constrained by material supply stresses. Raw material reserves, life-cycle impacts, and criticality could be used to adjust the technologies' costs in the TIAMFR model. This could be done by integrating raw materials and LCA metrics directly into the TIAMFR modeling structure. In this case, LCA, MFA and prospective scenario analysis could be achieved 
simultaneously to inform energy, resource, and environment decision-making regarding life-cycle aspects (Masanet et al. 2013). TIAM-FR is already capable of dealing with material flows and stocks in technology processes using specific parameters. However, achieving such an integration into the TIAM-FR model would necessitate considerable amounts of dynamic MFA data defining how material use might evolve over time, driven by efficiency changes, material substitution, economic reserves, prices, and many other parameters.

Evolution towards a circular economy is now recognized as a way to contribute to achieving the United Nations Sustainable Development Goals (SDGs) (European Commission 2015). As secondary material resources (i.e. recycled or reused) are expected to play an increasing role in the future (Ekins et al. 2016), investigating their implications in the TIAM-FR model could help determine more effective resource efficiency policies, especially in the context of climate change where environmental constraints are likely to exacerbate the stress on raw materials. Thus, an interesting extension to this work would be to analyze the build-up of in-use stocks and outflows of materials by distinguishing flows and stocks in the LCI datasets. Thermoecological approaches based on exergy and entropy (Stanek et al. 2017; Valero et al. 2015) appear to us promising ways to describe material cycles more physically.

Uncertainties were not addressed in this paper due to the fact that many sources of uncertainty are not identified (in LCIs) or currently impossible to quantify (in the TIAM-FR model). Further work is needed to understand how uncertainty can be better dealt with in more and more complex and integrated decision-making tools.

Transparency and reproducibility were motivations for using the ecoinvent database. At IEA, similar motivations led to the decentralization of the TIAM model, which is now used and developed by research teams in nearly seventy countries within the ETSAP community. However, it is clear that IAMs are still perceived as black boxes not only by the public but also by other research communities. This is why we subscribe to the ongoing discussions on open science and the need for more transparency in energy research (Pfenninger et al. 2018). 


\section{Conclusion}

Combining the TIAM-FR global energy system model with disaggregated life-cycle inventories enabled us to compute the prospective life-cycle requirements of fossil fuels and mineral resources due to electricity-generating technologies to 2100 . Fossil fuels and metallic and nonmetallic mineral resource requirements were computed in the construction, operation and decommissioning phases of the technologies, providing the first prospective assessment of mineral resource requirements by life phase and region. The results show that the development of hydro, solar and wind power generate increasing global demand for metallic and nonmetallic minerals within the next few decades in the scenario investigated, mainly due to their infrastructure. End-of-life capacities rapidly increase after 2040, which means more fossil fuels and mineral resources could be needed for decommissioning activities. The presented method can be adapted to investigate other prospective scenarios, and possibly other energy sectors, such as transportation, building construction and information technology. Total integration of raw materials into the TIAM-FR model still needs to be developed, as the current method does not allow endogenous interactions with the scenarios. This will require identifying those material-related parameters that may have a significant influence on the scenario (supply availability, material criticality, etc.). Eventually, LCA, MFA, and IAM may converge into a single tool to devise LCA-oriented energy and resource policies.

\section{References}

Ali, S.H., D. Giurco, N. Arndt, E. Nickless, G. Brown, A. Demetriades, R. Durrheim, et al. 2017. Mineral supply for sustainable development requires resource governance. Nature 543(7645): 367-372.

Arvesen, A., G. Luderer, M. Pehl, B.L. Bodirsky, and E.G. Hertwich. 2018. Deriving life cycle assessment coefficients for application in integrated assessment modelling. Environmental Modelling \& Software 99: 111-125.

B. Müller, D. 2006. Stock dynamics for forecasting material flows - Case study for housing in The Netherlands. Ecological Economics 59(1): 142-156.

Bruckner, T., I.A. Bashmakov, Y. Mulugetta, H. Chum, A. De la Vega Navarro, J. Edmonds, A. Faaij, et al. 2014. Energy systems. http://pure.iiasa.ac.at/11118. Accessed February 3, 2017.

Corona, B., D. Ruiz, and G.S. Miguel. 2016. Environmental Assessment of a HYSOL CSP Plant Compared to a Conventional Tower CSP Plant. Procedia Computer Science 83: 1110-1117. 
Daly, H.E., K. Scott, N. Strachan, and J. Barrett. 2015. Indirect CO2 emission implications of energy system pathways: linking IO and TIMES models for the UK. Environmental Science \& Technology 49(17): 10701-10709.

Drielsma, J.A., A.J. Russell-Vaccari, T. Drnek, T. Brady, P. Weihed, M. Mistry, and L.P. Simbor. 2016. Mineral resources in life cycle impact assessment — defining the path forward. The International Journal of Life Cycle Assessment 21(1): 85-105.

Dubreuil, A., E. Assoumou, S. Bouckaert, S. Selosse, and N. Ma1"zi. 2013. Water modeling in an energy optimization framework - The water-scarce middle east context. Applied Energy 101: 268-279.

Ekins, P., N. Hughes, S. Brigenzu, C. Arden Clark, M. Fischer-Kowalski, T. Graedel, M. Hajer, et al. 2016. Resource Efficiency: Potential and Economic Implications. http://pure.iiasa.ac.at/13813. Accessed February 14, 2017.

Elshkaki, A. and T.E. Graedel. 2013. Dynamic analysis of the global metals flows and stocks in electricity generation technologies. Journal of Cleaner Production 59: 260-273.

Energy Technology Systems Analysis Program. E-TechDS - Energy Technology Data Source. https://iea-etsap.org/index.php/energy-technology-data. Accessed March 31, 2018.

European Commission. 2015. Closing the loop - An EU action plan for the Circular Economy. European Commission, December 2. Accessed October 17, 2017.

European Commission, Joint Research Centre, and Institute for Environment and Sustainability. 2010. International Reference Life Cycle Data System (ILCD) Handbook - General guide for Life Cycle Assessment - Detailed guidance. Luxembourg: Publications Office.

Gerst, M.D. 2009. Linking Material Flow Analysis and Resource Policy via Future Scenarios of InUse Stock: An Example for Copper. Environmental Science \& Technology 43(16): 6320-6325. http://pubs.acs.org/doi/abs/10.1021/es900845v. Accessed January 24, 2017.

Gibon, T., A. Arvesen, and E.G. Hertwich. 2017. Life cycle assessment demonstrates environmental co-benefits and trade-offs of low-carbon electricity supply options. Renewable and Sustainable Energy Reviews 76: 1283-1290.

Gibon, T., R. Wood, A. Arvesen, J.D. Bergesen, S. Suh, and E.G. Hertwich. 2015. A Methodology for Integrated, Multiregional Life Cycle Assessment Scenarios under Large-Scale Technological Change. Environmental Science \& Technology 49(18): 11218-11226.

Graedel, T.E. 2011. On the Future Availability of the Energy Metals. Annual Review of Materials Research 41(1): 323-335. http://www.annualreviews.org/doi/10.1146/annurev-matsci-062910095759. Accessed January 31, 2017.

Halada, K., M. Shimada, and K. Ijima. 2008. Forecasting of the consumption of metals up to 2050. Materials Transactions 49(3): 402-410. http://jlc.jst.go.jp/DN/JALC/00309519401? from=Google. Accessed October 5, 2016.

Hertwich, E.G., T. Gibon, E.A. Bouman, A. Arvesen, S. Suh, G.A. Heath, J.D. Bergesen, A. Ramirez, M.I. Vega, and L. Shi. 2015. Integrated life-cycle assessment of electricity-supply scenarios confirms global environmental benefit of low-carbon technologies. Proceedings of the National Academy of Sciences 112(20): 6277-6282.

Hourcade, J.-C., M. Jaccard, C. Bataille, and F. Ghersi. 2006. Hybrid Modeling: New Answers to Old Challenges Introduction to the Special Issue of The Energy Journal. The Energy Journal SI2006(01). http://www.iaee.org/en/publications/ejarticle.aspx?id=2165. Accessed December 20, 2017.

International Energy Agency. 2005. Energy Statistics Manual. International Energy Agency. https://www.iea.org/publications/freepublications/publication/energy-statistics-manual.html.

International Energy Agency. 2016. World Energy Outlook 2016. S.1.

International Energy Agency. 2017. Headline Energy Data. IEA Publishing, October 1. https://www.iea.org/statistics/. Accessed October 1, 2017.

Kang, S., S. Selosse, and N. Maïzi. 2017. Is GHG mitigation policy enough to develop bioenergy in Asia: A long-term analysis with TIAM-FR. International Journal of Oil, Gas and Coal Technology 14(1-2): 5-31. 
Keramidas, K., A. Kitous, and B. Griffin. 2012. Future availability and demand for oil gas and key minerals. Working paper n. 30. POLINARES European project. March. http://pratclif.com/2015/mines-ressources/polinares/chapter18.pdf. Accessed February 15, 2017.

Kleijn, R., E. van der Voet, G.J. Kramer, L. van Oers, and C. van der Giesen. 2011. Metal requirements of low-carbon power generation. Energy 36(9): 5640-5648.

Koning, A. de, R. Kleijn, G. Huppes, B. Sprecher, G. van Engelen, and A. Tukker. 2018. Metal supply constraints for a low-carbon economy? Resources, Conservation and Recycling 129: 202-208.

Loulou, R. and M. Labriet. 2008. ETSAP-TIAM: the TIMES integrated assessment model Part I: Model structure. Computational Management Science 5(1-2): 7-40.

Majeau-Bettez, G., A.H. Strømman, and E.G. Hertwich. 2011. Evaluation of Process- and InputOutput-based Life Cycle Inventory Data with Regard to Truncation and Aggregation Issues. Environmental Science \& Technology 45(23): 10170-10177.

Masanet, E., Y. Chang, A.R. Gopal, P. Larsen, W.R. Morrow, R. Sathre, A. Shehabi, and P. Zhai. 2013. Life-Cycle Assessment of Electric Power Systems. Annual Review of Environment and Resources 38(1): 107-136.

McDowall, W., B. Solano Rodriguez, A. Usubiaga, and J. Acosta Fernández. 2018. Is the optimal decarbonization pathway influenced by indirect emissions? Incorporating indirect life-cycle carbon dioxide emissions into a European TIMES model. Journal of Cleaner Production 170: 260-268.

O’Neill, B.C., E. Kriegler, K. Riahi, K.L. Ebi, S. Hallegatte, T.R. Carter, R. Mathur, and D.P. van Vuuren. 2014. A new scenario framework for climate change research: the concept of shared socioeconomic pathways. Climatic Change 122(3): 387-400.

Pauliuk, S., A. Arvesen, K. Stadler, and E.G. Hertwich. 2017. Industrial ecology in integrated assessment models. Nature Climate Change 7(1): 13-20.

Pauliuk, S. and E.G. Hertwich. 2016. Prospective Models of Society's Future Metabolism: What Industrial Ecology Has to Contribute. In Taking Stock of Industrial Ecology, ed. by Roland Clift and Angela Druckman, 21-43. Cham: Springer International Publishing. http://dx.doi.org/10.1007/978-3-319-20571-7_2.

Pauliuk, S., G. Majeau-Bettez, C.L. Mutel, B. Steubing, and K. Stadler. 2015. Lifting Industrial Ecology Modeling to a New Level of Quality and Transparency: A Call for More Transparent Publications and a Collaborative Open Source Software Framework: Open Source Software for Industrial Ecology. Journal of Industrial Ecology 19(6): 937-949.

Pehl, M., A. Arvesen, F. Humpenöder, A. Popp, E.G. Hertwich, and G. Luderer. 2017. Understanding future emissions from low-carbon power systems by integration of life-cycle assessment and integrated energy modelling. Nature Energy 2(12): 939-945.

Pfenninger, S., L. Hirth, I. Schlecht, E. Schmid, F. Wiese, T. Brown, C. Davis, et al. 2018. Opening the black box of energy modelling: Strategies and lessons learned. Energy Strategy Reviews 19: 63-71.

San Miguel, G., B. Corona, and D. Ruiz. 2016. D6.3 Full Life Cycle Analysis of HYSOL Technology: Environmental and socio-economic assessment. HYSOL project - FP7-ENERGY-2012-1 - CP 308912. July.

Schandl, H., M. Fischer-Kowalski, J. West, S. Giljum, M. Dittrich, N. Eisenmenger, A. Geschke, et al. 2017. Global Material Flows and Resource Productivity: Forty Years of Evidence: Global Material Flows and Resource Productivity. Journal of Industrial Ecology. http://doi.wiley.com/10.1111/jiec.12626. Accessed April 27, 2018.

Selosse, S. and O. Ricci. 2014. Achieving negative emissions with BECCS (bioenergy with carbon capture and storage) in the power sector: New insights from the TIAM-FR (TIMES Integrated Assessment Model France) model. Energy 76: 967-975.

Stanek, W., J. Szargut, and S. Usón. 2017. Fundamentals of Exergy Analysis. In Thermodynamics for Sustainable Management of Natural Resources, ed. by Wojciech Stanek, 37-80. Cham: Springer International Publishing. http://link.springer.com/10.1007/978-3-319-48649-9_3. Accessed October 17, 2017. 
Steubing, B., G. Wernet, J. Reinhard, C. Bauer, and E. Moreno-Ruiz. 2016. The ecoinvent database version 3 (part II): analyzing LCA results and comparison to version 2. The International Journal of Life Cycle Assessment 21(9): 1269-1281.

U.S. Energy Information Administration. 2017. International Energy Outlook. Energy Information Administration, February 9. https://www.eia.gov/outlooks/ieo/pdf/0484(2016).pdf. Accessed February 9, 2017.

Valero, A., M. Valdés, and G. Calvo. 2015. Exergy as a resource efficiency indicator for industries. In ECOS 2015 - 28th International Conference on Efficiency, Cost, Optimization, Simulation and Environmental Impact of Energy Systems. https://www.scopus.com/inward/record.uri?eid=2s2.0-84978877446\&partnerID=40\&md5=f4af6341a773e67d2c9854081a4087f1. Accessed June 29, 2015.

Van Vuuren, D.P., B.J. Strengers, and H.J. De Vries. 1999. Long-term perspectives on world metal use —a system-dynamics model. Resources Policy 25(4): 239-255. http://www.sciencedirect.com/science/article/pii/S0301420799000318. Accessed January 24, 2017.

Vidal, O., B. Goffé, and N. Arndt. 2013. Metals for a low-carbon society. Nature Geoscience 6(11): 894-896.

Wernet, G., C. Bauer, B. Steubing, J. Reinhard, E. Moreno-Ruiz, and B. Weidema. 2016. The ecoinvent database version 3 (part I): overview and methodology. The International Journal of Life Cycle Assessment 21(9): 1218-1230.

World Energy Council. 2016. World Energy Scenarios 2016. October. https://www.worldenergy.org/wp-content/uploads/2016/10/World-Energy-Scenarios2016_Full-report.pdf. Accessed February 8, 2017. 